\title{
LAZER - UM CAMINHO PARA ALIVIAR AS TENSÕES NO AMBIENTE DE TRABALHO EM UTI: UMA CONCEPÇÃO DA EQUIPE DE ENFERMAGEM
}

Maria Elizabeth Roza Pereira* Sônia Maria Villela Bueno**

PEREIRA, M.E.R.; BUENO, S.M.V. Lazer - Um caminho para aliviar as tensões no ambiente de trabalho em UTI: uma concepção da equipe de enfermagem. Rev.latino-am.enfermagem, Ribeirão Preto, v. 5, n. 4, p. 75-83, outubro 1997.

Propusemos neste estudo, verificar com uma equipe de enfermagem de UTI, a representação do serviço e o significado desta unidade, levantando também, o sentido do lazer e sua implicação no ambiente profissional. Trabalhamos o referencial teórico de DUMAZEDIER, enfocando o lazer na promoção da saúde. Então, investigamos 10 membros desta equipe, de um hospital mineiro. O grupo pesquisado é constituído na maioria, de mulheres, solteiras, entre 28 e 45 anos, com predominância de mais de 10 anos de experiência no serviço. $90 \%$ desses, evidenciam gostar do trabalho, embora reconhecendo ser desgastante e estressante (50\%). Identificam o serviço sobretudo como assistencial (80\%), exigindo vocação/doação (50\%). Questionam a sua dura jornada de trabalho (60\%), sugerindo redução de horas. Revelam problemas de relacionamento/comunicação no serviço. Conceituam lazer como diversão/ descontração (80\%); relaxamento (20\%), etc, ressaltando necessidade de discussão do assunto. Admitem tensão/estresse no local, revelando importância de lazer no serviço, para favorecer a comunicação e alivio de tensões. Sugerimos aos enfermeiros investimento nesta área.

UNITERMOS: unidade de terapia Intensiva (UTI), lazer, equipe de Enfermagem

\section{INTRODUÇÃO}

Referenciais teórico - práticos que abordam as questões da complexidade existente, em serviço de Unidade de Terapia Intensiva (UTI), revelam - nos a importância de se rever as questões que permeiam o relacionamento interpessoal da equipe de enfermagem neste contexto, tendo em vista, os problemas emergidos das circunstâncias em que as peculiaridades do ambiente ocasionam aos seus profissionais/ocupacionais. Evidenciam ainda, o nível de ansiedade e tensão, provocado sobretudo pela elevada responsabilidade que a enfermagem enfrenta em seu cotidiano profissional, nesta unidade.

Este fato ocorre, devido as consequiências das variáveis que intervêm neste processo, tais como: ambiente extremamente seco, refrigerado, fechado e iluminação artificial; ruído interno contínuo e intermitente; inter-relacionamento constante entre as mesmas pessoas da equipe, durante todo o turno, bem como, a exigência excessiva de segurança, respeito e responsabilidade para o paciente, em sofrimento, dor e com morte iminente, para a garantia da qualidade da assistência. Esses indicadores certamente, resultam em um clima de trabalho exaustivo e tenso, provocando desmotivação, conflito entre os membros da equipe e estresse ao grupo de trabalho e em particular, ao trabalhador, individualmente.

Embasadas nestes dados e sensibilizadas com estas questões, depreendemos ser de fundamental importância, a atenção especial a estes profissionais/ ocupacionais, tendo em vista, a necessidade da busca de meios propícios que venham promover a saúde integral do trabalhador. Para tanto, procuramos aqui, levar em consideração: o trabalhador, o ambiente profissional, o estresse e o lazer no contexto hospitalar.

Neste sentido, entendemos que o lazer tem papel fundamental enquanto meio alternativo para o relaxamento e alívio dos problemas advindos da contextualidade e do cotidiano do indivíduo, seja ao nível pessoal quanto profissional. Voltando estas questões para o pessoal de enfermagem que trabalha na UTI, o desenvolvimento de atividades de lazer é relevante no favorecimento da comunicação entre eles, no relacionamento interpessoal, bem como, no alívio das tensões, visando pois, a educação para a melhoria da qualidade de vida do trabalhador e do serviço, em geral.

\footnotetext{
* Mestranda em Enfermagem Psiquiátrica do Dpto. EPCH da EERP - USP e Enfermeira da UTI do Hospital de Clínicas da Universidade Federal de Uberlândia - UFU

** Professora Doutora do Departamento de Enfermagem Psiquiátrica e Ciências Humanas da Escola de Enfermagem de Ribeirão Preto da Universidade de São Paulo (Pedagoga)
} 
Sendo assim, no presente estudo o referencial teórico utilizado, está centrado no contexto da UTI, tendo em vista ser ele um ambiente gerador de estresse e que exige dos membros da equipe, refazimento dos níveis de tensão. A partir daí, é que se propõe neste ensaio, a utilização do lazer para promoção da saúde do trabalhador e do ambiente profissional em questão.

\section{REFERENCIAL TEÓRICO}

\section{Condições estressoras do ambiente de trabalho}

TESCK (1982), pesquisou os fatores de estresse a que a equipe de enfermagem que trabalha em UTI está exposta, apontando os indicadores que se caracterizam em três níveis: ambiente, equipe e relação enfermeiropaciente-família.

Neste sentido, partindo do pressuposto de que o nível de estresse é alto, GOMES (1988) refere que isto ocorre devido a vários fatores. Dentre eles, cita, por exemplo, as características da UTI, a qual é constituída por: 1- ambiente fechado, 2- iluminação artificial, 3- ar condicionado, o qual sabemos que pode levar a alterações de humor, as pessoas passam a se mostrar irritadas sem motivo aparente, alergias, cefaléias, ansiedade, entre outros, 4- planta física, às vezes inadequada ao serviço de enfermagem, 5- supervisão/coordenação vigilantes com cobranças constantes, 6- rotinas exigentes, 7deficiência de recursos humanos, 8- equipamentos sofisticados e barulhentos, 9- morte, dor e sofrimento como entidades fortes neste ambiente, gerando uma falta de motivação, muitas vezes, para o trabalho.

Este fato poderá contribuir para o aumento do grau de tensão entre os trabalhadores deste local, podendo também, prejudicar o bom andamento da equipe e do serviço. (CORRÊA, 1995).

Nossa inquietação está justamente aí, como ponto fundamental de reflexão. Temos observado que os funcionários em situação de estresse e exaustão, demonstram interesse compulsivo em buscar maneiras efetivas para melhorar o seu estado geral, mas também, de melhorar o seu ambiente de trabalho. Eles expressam constante desejo, em seus momentos livres, de bater-papo informalmente, tomar café, por várias vezes, no seu horário de serviço, refazer-se na hora do almoço e nas horas de descanso noturno, ver televisão, ouvir música, ler revista ou livro e usufruir de um lugar para o breve repouso com mais conforto, entre outros, como forma de refazimento físico e mental.(SEBASTIANI, s.d.)

\section{Condições favoráveis de alívio de tensões no trabalho}

Segundo DUMAZEDIER (1974), o lazer é de considerável relevância na vida das pessoas. Para o autor, a ética do lazer não é a da ociosidade que rejeita o trabalho, nem a da licença que infringe as obrigações, mas a de um novo equilíbrio entre as exigências utilitárias da sociedade e as exigências desinteressadas da pessoa.

O lazer enquanto promoção da saúde integral, tem três funções primordiais. São elas: a de descanso, de divertimento (distração, recreação e entretenimento) e de desenvolvimento da personalidade. (Dumazedier apud BUENO, 1981)

A primeira função é a de descanso, descontração ou recuperação. Essa ocorre quando o lazer é um reparador das deteriorações das forças físicas e mentais, provocadas pelas tensões resultantes das obrigações cotidianas e, particularmente, do trabalho. A segunda função é a de divertimento, recreação e entretenimento, entre as quais, o indivíduo poderá optar, de acordo com sua livre escolha, opondo-se contra o tédio ou estresse, causado pelo trabalho do dia a dia. Esta função compreende ainda, das ocupações inspiradas pela necessidade de distração, com ou sem predominância artística. A terceira função está ligada ao desenvolvimento da personalidade. Esta se processa quando o indivíduo é capaz de agir e de pensar, livre de condicionamentos que lhe automatizam a ação e o pensamento. A prática das atividades de lazer fornece ao indivíduo, condições de se desenvolver, conforme vá aumentando ou recebendo elementos que, desinteressadamente, o formam. Esta função ressalta os elementos que conduzem o indivíduo ao seu pleno desenvolvimento, condição para seu bem estar social e para uma participação mais ativa no atendimento das necessidades de ordem individual, familiar, profissional, cultural e comunitária (DUMAZEDIER,1973; MAGNANE, 1969; REQUIXA, s.d.).

Em contraposição ao trabalho, o lazer favorece consideravelmente, o nível de saúde integral e sobretudo mental das pessoas, canalizando as energias perdidas para os aspectos saudáveis, aliviando assim, a fadiga exaustiva e o estresse provocados pelas condições desfavoráveis da contextualidade das pessoas em geral. (DUMAZEDIER, 1979; BUENO, 1981).

Repensando estas questões, consideramos ser relevante que, nos momentos livres de trabalho, fora ou dentro da unidade de serviço, a equipe de enfermagem, possa desenvolver atividades de lazer, como meios de reeducação, de refazimento físico, mental, social e espiritual bem como, forma de distração, recreação, entretenimento, de comunicação, motivação e alívio de tensão.

A partir destes referenciais, é que propomos o presente estudo, de acordo com os objetivos seguintes. 


\section{OBJETIVOS}

- verificar com a equipe de enfermagem da UTI, o que representa o seu ambiente de trabalho e qual o significado dessa unidade, para ela;

- detectar o pensamento da equipe de enfermagem sobre as jornadas de trabalho em UTI;

- identificar quais os problemas no serviço que levam a desmotivação no trabalho;

- averiguar o interesse pela existência de lazer e/ou recreação, no ambiente de trabalho, junto à população estudada.

\section{METODOLOGIA}

Trata-se de uma pesquisa com abordagem humanista, de cunho quali-quantitativo, entendendo-a como qualitativa, à medida que procuramos compreender, analisar e interpretar o conteúdo expresso nas unidades de pensamento, emitido pela população estudada. E quantitativa, quando procuramos buscar, no inquérito de opiniões, o consenso da equipe de enfermagem sobre os dados levantados, em relação aos objetivos propostos.

Utilizamos o referencial teórico de DUMAZEDIER (1973, 1974, 1979), que enfatiza o lazer enquanto forma relevante de reposição de forças perdidas causadas pela fadiga exaustiva do trabalho cotidiano, visando assim, a promoção da saúde integral das pessoas, tanto particular e profissionalmente, quanto em grupo.

Levando-se em consideração esta fundamentação e por saber das implicações destes fatores que a equipe de saúde e especialmente da enfermagem enfrentam na UTI, devido às próprias peculiaridades deste contexto, procuramos investigar os profissionais/ocupacionais de enfermagem (enfermeiros, técnicos e auxiliares), de uma Unidade de Terapia Intensiva (UTI) do Hospital de Clínicas, da Universidade Federal de Uberlândia - MG.

Para o levantamento dos dados, utilizamos as técnicas da observação e da entrevista individual e coletiva, usando como instrumento, o questionário, tendo como roteiro, questões norteadoras.

\section{I - DADOS DE IDENTIFICAÇÃO: II - QUESTÕES NORTEADORAS:}

1. O que você acha do seu serviço?

2. O que representa o serviço da UTI para você?

3. O que você acha da jornada de trabalho, na UTI?

4. Quais os problemas que você enfrenta no seu serviço, que o desestimula ao trabalho?

5. O que você entende por lazer? Gostaria de conhecer e discutir questões relativas a esse assunto, em seu serviço? 6. O que você pensa sobre a criação de atividades de lazer e recreação em alguns momentos, no seu serviço?

Para podermos compreender e interpretar, de forma efetiva os resultados, aplicamos a instrução dos procedimentos de GIORGI para análise da categorização, citados por Vietta \& Bueno, apud BUENO (1993).

O procedimento utilizado por nós, na presente pesquisa, seguiu os seguintes passos:

1. Observação e constatação dos elementos estressores do ambiente da UTI,

2. Elaboração do projeto e definição dos objetivos propostos,

3. Construção do instrumento de coleta de dados para o plano piloto,

4. Testagem e validação do instrumento do plano piloto, que culminou com este estudo,

5. Realização da entrevista: Todos os sujeitos que participaram da presente investigação, são membros da equipe de enfermagem da UTI. A seleção foi aleatória. Realizamos uma reunião com todos os profissionais presentes naquele momento, onde esclarecemos os propósitos deste estudo e pedimos a colaboração dos mesmos ressaltando a importância da participação efetiva de todos. Apenas não participaram, os que estavam de férias ou folga. A população escolhida foi a equipe de enfermagem, composta por enfermeiros, técnicos e auxiliares. A coleta de dados deu-se no $1^{\circ}$ semestre de 1996, com observação simultânea, onde integramos profissionalmente como membro desta equipe de enfermagem o que nos possibilitou, ouvi-los e discutir com os mesmos seus problemas no cotidiano profissional, suas percepções sobre o trabalho e os seus anseios em buscar meios para tentar solucioná-los. A entrevista foi conduzida no próprio local de serviço, isto é, na UTI, durante os horários de trabalho dos profissionais, em seus turnos diurnos ou noturnos, respectivamente, com duração de vinte(20) a trinta(30) minutos, cada entrevista. Foi elaborado um questionário com dados de identificação e com questões norteadoras abertas (anexo 1), as quais foram respondidas oral e individualmente; usando então,a gravação para este fim.

6. Levantamento das matrizes dos dados coletados,

7. Utilização da instrução para a categorização dos dados levantados. Isto implicou em:

- leitura atentiva do conteúdo expresso pelos sujeitos pesquisados; utilização das unidades de pensamento, para categorização das falas dos entrevistados; classificação e interpretação das falas apresentadas nas tabelas e quadros trabalhados.

8. Análise e conclusão dos resultados. 


\section{RESULTADOS E DISCUSSÃO}

Neste estudo, procuramos apresentar os resultados seguidos das respectivas discussões. Iniciaremos pois, com a caracterização da população, partindo a seguir para a apresentação e a análise das questões do tema central.

Conforme o Quadro 1, os sujeitos pesquisados se identificam como sendo 10 membros da equipe de enfermagem ( 2 enfermeiros, 5 técnicos e 3 auxiliares): 90\% de mulheres; $50 \%$ de solteiros; $70 \%$ de católicos; maioria com idade superior a 36 anos, predominando entre eles, um tempo de serviço, acima de 10 anos. Isto nos infere interpretar que trata-se de um profissional que já tras considerável bagagem prática, pelo menos, adquirido em seu trabalho cotidiano.

Quadro 1 - Representação numérica e percentual das respostas dos membros da equipe de enfermagem sobre sua identificação pessoal e profissional. $1^{\circ}$ semestre de 1996

\begin{tabular}{|c|c|c|}
\hline $\begin{array}{l}\text { IDENTIFICACÃOPESSOAL } \\
\text { E PROFISSIONAL }\end{array}$ & NÚMERO & $\%$ \\
\hline $\begin{array}{l}\text { SEXO } \\
\text { ferninino } \\
\text { masculino } \\
\text { TOTAL }\end{array}$ & $\begin{array}{c}9 \\
1 \\
10\end{array}$ & $\begin{array}{c}90 \\
10 \\
100\end{array}$ \\
\hline $\begin{array}{l}\text { FAIXA ETARIA } \\
\leq 30 \\
31-35 \\
36-40 \\
41 \geq \\
\text { TOTAL }\end{array}$ & $\begin{array}{c}3 \\
1 \\
3 \\
3 \\
10\end{array}$ & $\begin{array}{l}30 \\
10 \\
30 \\
30 \\
100\end{array}$ \\
\hline $\begin{array}{l}\text { ESTAD O CIVIL } \\
\text { solteiro } \\
\text { casado } \\
\text { separado/divorciado } \\
\text { TOTAL }\end{array}$ & $\begin{array}{c}5 \\
3 \\
2 \\
10\end{array}$ & $\begin{array}{c}50 \\
30 \\
20 \\
100\end{array}$ \\
\hline $\begin{array}{l}\text { RELI GIÃO } \\
\text { católica } \\
\text { espírita } \\
\text { evangélica } \\
\text { TOTAL }\end{array}$ & $\begin{array}{c}7 \\
2 \\
1 \\
10\end{array}$ & $\begin{array}{c}70 \\
20 \\
10 \\
100\end{array}$ \\
\hline $\begin{array}{l}\text { PROFIS SÃ O/OCUPAÇÃO } \\
\text { enfermeiros } \\
\text { técricos } \\
\text { auxiliares } \\
\text { TOTAL }\end{array}$ & $\begin{array}{c}2 \\
5 \\
3 \\
10\end{array}$ & $\begin{array}{l}20 \\
50 \\
30 \\
100\end{array}$ \\
\hline $\begin{array}{l}\text { TEMP O DE SERVÇO NA } \\
\text { ENF ERMA GEM/UTI } \\
\leq 5 \\
6-10 \\
11-15 \\
16 \geq \\
\text { TOTAL }\end{array}$ & $\begin{array}{c}3 \\
1 \\
5 \\
1 \\
10\end{array}$ & $\begin{array}{c}30 \\
10 \\
50 \\
10 \\
100\end{array}$ \\
\hline
\end{tabular}

Referindo-se a questão - "o que você acha do seu serviço", o Quadro 2 nos evidencia que, embora a grande maioria (90\%) tenha revelado gostar do seu serviço, todavia, quase todos mencionaram que trabalhar na UTI, "é estressante"; "desgastante"; “cansativo", entre outros.

Com relação as respostas de que o trabalho na UTI é estressante, gostaríamos de ressaltar que o estresse é decorrente das nossas relações humanas e que não existe possibilidade de vivenciá-las sem indicadores estressores. Este estresse também decorre do ambiente, das condições e ritmo de trabalho, da estrutura organizacional, e no caso do hospital, na UTI principalmente, temos ainda as rotinas exigentes, convívio com o sofrimento e a morte, imprevisibilidade, conflitos em relação aos vínculos de afinidade com pacientes, hierarquia informal com demais profissionais e carga horária de trabalho.

Por outro lado, na UTI, nós temos também fatores que diminuem o estresse e as tensões, dentre eles vale lembrar que as relações interpessoais mais estreitas entre os profissionais e contato mais direto com o paciente, aumentam a auto-realização e a auto-estima, o ambiente mais organizado, melhor equipado em recursos materiais de qualidade e humanos bem qualificados. $\mathrm{Na}$ UTI, temos maiores possibilidades de reconhecimento enquanto pessoa e enquanto profissional.

Diante destas colocações podemos concluir que o estresse embora tenha seus aspectos negativos, também tem seus aspectos positivos, quando motiva e estimula o indivíduo para o trabalho, para o crescimento pessoal e profissional, fazendo-o buscar o real significado da vida, isso certamente, será revertido para satisfação individual e coletiva.

Quadro 2 - Representação numérica e percentual das respostas dos membros da equipe de enfermagem sobre a questão: “o que você acha do seu trabalho?"

\begin{tabular}{|c|c|c|}
\hline $\begin{array}{l}\text { RESPOSTAS: "O serviço } \\
\text { desperta" }\end{array}$ & NÚMERO & $\% *$ \\
\hline $\begin{array}{l}\text { SENTIMENT OS DE PRAZER } \\
\text { "É uma experiência gostosa"; "gosto } \\
\text { do meu trabalho", "gosto do que faço } \\
\text { e da profissão"; "adoro e sinto bem } \\
\text { em trabalhar"; "gosto bastante". } \\
\text { "É muito gratificante, importante". } \\
\text { "É muito bom, gosto demais". }\end{array}$ & $\frac{1}{3}$ & $\begin{array}{l}10 \\
30\end{array}$ \\
\hline $\begin{array}{l}\text { SENTIMENTOS DE ESTRESSE } \\
\text { "A pesar de go star"; "acho } \\
\text { estressante";"é desgastante". } \\
\text { "É cansativo, mas é o que tenho que } \\
\text { fazer". } \\
\text { "As vezes, me sinto bloqueado". }\end{array}$ & $\begin{array}{l}3 \\
1 \\
1\end{array}$ & $\begin{array}{l}30 \\
10 \\
10\end{array}$ \\
\hline $\begin{array}{l}\text { OUTROS } \\
\text { "Estar com o paciente é bom, mas } \\
\text { dificil é lidar com a familia". } \\
\text { "Profissão limitada". } \\
\text { "Não reconhecida". } \\
\text { "Tem que ter dom". }\end{array}$ & $\begin{array}{l}1 \\
1 \\
1 \\
1\end{array}$ & $\begin{array}{l}10 \\
10 \\
10 \\
10\end{array}$ \\
\hline
\end{tabular}

* A \% foi calculada pelo total da população estudada (10). Houve mais de uma resposta em alguns casos 
Na questão - "O que representa o serviço da UTI para você", o Quadro 3 nos mostra que $80 \%$ dos membros da equipe de enfermagem, evidenciam o serviço enquanto fonte de atendimento assistencial, onde o cuidado é "mais direcionado ao paciente", "é mais freqüente": onde se dá mais "atenção"; "melhor cuidado"; "lugar de recuperação", e "de vida e não de morte". Metade dos sujeitos estudados, identificam este tipo de trabalho enquanto fonte de sentimento vocacionado $e$ de doação, quando expressam o seguinte: "é uma forma de doar um pouco...", "foi uma grande descoberta em minha vida", "é onde a gente se realiza", "me sinto útil e realizada", "é onde se dá ajuda e salva as pessoas". Esta forma de evidenciar o trabalho, possivelmente, se deva por fatores influentes como formação profissional; pela formação religiosa de cada um, assim como, pelas próprias circunstâncias em que o pessoal de enfermagem em UTI, enfrenta no seu cotidiano profissional, ao lidar com o sofrimento iminente e com algumas situações em que a morte torna-se evidente. Para a identificação da UTI enquanto fonte de relacionamento/comunicação, $40 \%$ dos sujeitos estudados enfocam o local como meio propício para "relacionamento social", "relacionamento de pessoa a pessoa", "onde se pode conviver" e "onde pode haver maior diálogo". Aparecem outras fontes como: de crescimento; de conhecimento, entre outras.

Quadro 3 - Representação numérica e percentual das respostas dos membros da equipe de enfermagem sobre a questão: “o que representa a UTI para você?"

\begin{tabular}{|c|c|c|}
\hline RESPOSTAS: "Representação da UTI" & NÚMERO & $\% *$ \\
\hline $\begin{array}{l}\text { FONTE DE SEN TIMENT O VOCACIONADO E DE DOACÃO } \\
\text { - "É uma forma de me doar um pouco, é uma forma de viver"; "grande } \\
\text { descoberta na minha vida"; "onde a gente se realiza"; "me sinto útil e } \\
\text { realizada"; "onde se dá ajuda e salva pessoas". }\end{array}$ & 5 & 50 \\
\hline $\begin{array}{l}\text { FONTE DE ATENDIMENTO ASSISTENCIAL } \\
\text { "Onde se presta assistência", "onde o cuidado é mais direcionado ao } \\
\text { paciente"; "onde o cuidado é mais freqüente"; "onde o paciente tem mais } \\
\text { cuidado e atenção"; "onde se dá melhor cuidado"; "lugar de recuperação"; } \\
\text { "salva do sofrimento"; "a UTI é vida e não morte". }\end{array}$ & 8 & 80 \\
\hline $\begin{array}{l}\text { FONTE RELACIONAMENT O/COMUNICACÃO } \\
\text { - "Local de relacionamento social"; "de relacionamento de pessoa a } \\
\text { pesssoa"; "onde pode haver maior diálogo"; "onde se pode conviver". }\end{array}$ & 4 & 40 \\
\hline $\begin{array}{l}\text { FONTE DE CONHECIMENTO } \\
\text { - "Lugar que proporciona conhecimento"; "dá para conhecer mais sobre } \\
\text { o outro"; "dá visão ampla". }\end{array}$ & 3 & 30 \\
\hline $\begin{array}{l}\text { FONTE DE CRESCIMENTO } \\
\text { - "Lugar de crescimento pessoal" e "profissional". }\end{array}$ & 2 & 20 \\
\hline $\begin{array}{l}\text { OUTROS } \\
\text { - "Lugar que me distrai"; } \\
\text { - "Espaço pequeno"; } \\
\text { - "Se conhece pouco sobre o paciente"; } \\
\text { - "Forma de estar vivendo". }\end{array}$ & $\begin{array}{l}1 \\
1 \\
1 \\
1\end{array}$ & $\begin{array}{l}10 \\
10 \\
10 \\
10\end{array}$ \\
\hline EM BRANCO & 1 & 10 \\
\hline
\end{tabular}

* A \% foi calculada pelo total da população estudada (10). Houve mais de uma resposta em alguns casos

Sobre a questão - "o que você acha da carga horária de trabalho na UTI", o Quadro 4 nos revela que a grande maioria dos profissionais/ocupacionais de enfermagem investigados, sente necessidade de diminuição em horas da sua jornada de trabalho. Alguns até sugerem que se limite, pelo menos, a 6 horas para todos os turnos. Há menção também, de que se pudesse, deveria ter "férias duas vezes ao ano", sobretudo pela 
caracterização do ambiente, como sendo "duro".

Em relação a estas respostas, gostaríamos de complementar com os referenciais de DUMAZEDIER (1979), que diz: "quando se aumenta a duração do tempo livre, esse é ocupado pelos trabalhadores sobretudo com atividades familiares". Este autor continua, citando $\mathrm{H}$. Kahn e A. Wiener, os quais colocam que para o ano 2000 , existirá um capitalismo produtivista e humanitário que reduzirá o tempo livre de trabalho na sociedade americana; tanto com a diminuição da jornada de trabalho semanal, como também será estendido para o aumento das férias anuais dos trabalhadores. Portanto, temos que, para cada sociedade, existe uma tendência evolutiva que determina o seu crescimento, mas na verdade e apesar dessa diversidade, acreditamos que os trabalhadores em geral, suscitam por aumentar a duração do seu tempo livre, para nesse momento, fazer tudo e qual coisa que ele bem entender ou ser lícito.

Quadro 4 - Representação numérica e percentual das respostas dos membros da equipe de enfermagem sobre a questão: “o que você acha da carga horária de trabalho, na UTI?"

\begin{tabular}{|l|c|c|}
\hline $\begin{array}{l}\text { RESPOSTAS: "Carga horária, } \\
\text { na UTI" }\end{array}$ & NUMMERO & $\% *$ \\
\hline $\begin{array}{l}\text { NECESSIDADE DE REDUÇÃO } \\
\text { DAJORNADA DE TRABALHO } \\
\text { - "Deveria ser menor"; "reduzida"; } \\
\text { "diminuida"; "menor". }\end{array}$ & 6 & 60 \\
$\begin{array}{l}\text { - Deveria ser 6 horas como limite } \\
\text { máximo"; "isto seria ideal"; "mas } \\
\text { deve manter 6 horas em todos os } \\
\text { turnos". }\end{array}$ & 3 & 30 \\
\hline $\begin{array}{l}\text { OUTROS } \\
\text {-"Deveria ter férias duas vezes ao } \\
\text { ano"; } \\
\text { - "Não é muito, mas o ambiente é } \\
\text { duro"; } \\
\text { - "Está ótimo". }\end{array}$ & 1 & 10 \\
\hline
\end{tabular}

* A \% foi calculada pelo total da população estudada (10). Houve mais de uma resposta em alguns casos.

Para a questão - "Quais os problemas que você enfrenta no seu serviço, que o desestimula ao trabalho?", o Quadro 5 nos mostra que os maiores problemas do pessoal estudado, residem na dificuldade de relacionamento e de comunicação (60\%). Surgiram outros problemas em menor escala, tais como: "falta de profissionalismo", "falta de reconhecimento" e "desigualdade". Depreendemos então, de que o próprio estresse provocado pelas condições de trabalho, acaba interferindo no relacionamento das pessoas, em equipe.

Quadro 5 - Representação numérica e percentual das respostas dos membros da equipe de enfermagem sobre a questão: "quais os problemas que você enfrenta no seu serviço que o desestimulam ao trabalho?"

\begin{tabular}{|l|c|c|}
\hline $\begin{array}{l}\text { RESPOSTA: "Problemas } \\
\text { desestimuladores do } \\
\text { trabalho" }\end{array}$ & NÚMERO & $\% *$ \\
\hline $\begin{array}{l}\text { PROBLEMAS DE RELACIO- } \\
\text { NAMENTO }\end{array}$ & & \\
\hline $\begin{array}{l}\text { - Desunião de todos"; "falta de } \\
\text { coleguismo". }\end{array}$ & 4 & 40 \\
\hline $\begin{array}{l}\text { PROBLEMAS DE COMUNICA- } \\
\text { CÃO } \\
\text { - "Falta de comunicação"; "de diá- } \\
\text { logo". }\end{array}$ & 2 & 20 \\
\hline $\begin{array}{l}\text { OUTROS } \\
\text { - "Falta de profissionalismo"; }\end{array}$ & 1 & 10 \\
- "Falta de reconhecimento"; & 1 & 10 \\
- "Desigualdade". & 1 & 10 \\
\hline EM BRANCO & 1 & 10 \\
\hline
\end{tabular}

* A \% foi calculada pelo total da população estudada (10). Houve mais de uma resposta em alguns casos

Depois de levantarmos as questões para verificar a opinião dos sujeitos investigados, em relação ao seu serviço e sua inserção no seu ambiente de trabalho, pudemos identificar os seus problemas, o que nos revelou existir excesso de atividades, e considerável estresse no seu cotidiano, devido as peculiaridades do próprio contexto em que presta assistência.

Por outro lado, neste momento, passaremos a analisar e refletir sobre as questões levantadas sobre lazer no ambiente profissional, identificando com os sujeitos trabalhados, o seu conceito, assim, sua percepção sobre a aplicabilidade de atividades de descontração, recreação e entretenimento, na sua vida profissional.

Ao levantar o significado de lazer, junto à equipe de enfermagem pesquisada, conforme o Quadro 6, na questão- "o que você entende por lazer? Gostaria de conhecer e discutir questões relativas a esse assunto, em seu serviço", a grande maioria conceitua o lazer, relacionando-o à "diversão", "distração" (80\%); de ter vida social, como dançar, passear, estar com amigos, etc. $(70 \%)$; à relaxamento (20\%) e como forma de "arejar 
a cabeça" e "em não pensar em nada"(20\%); livre de obrigatoriedade (10\%); aproveitando das "horas de folga". Portanto, embora de forma simples e ingênua, estes sujeitos apresentam uma idéia real sobre a semântica do lazer, indo de encontro com o conceito de lazer, preconizado por DUMAZEDIER (1973). Quanto ao interesse em conhecer e discutir este assunto, articulado com o ambiente de trabalho, $90 \%$ responderam positivamente esta questão.

Requixa, adepto de Dumazedier refere que quando o indivíduo tem conhecimento e interpreta o significado do lazer, encontrando condições favoráveis para sua prática, isso torna-se uma das mais importantes providências para a humanização do ambiente. (REQUIXA, 1977).

Quadro 6 - Representação numérica e percentual das respostas dos membros da equipe de enfermagem sobre a questão: “o que você entende por lazer? gostaria de conhecer e discutir sobre este tema?"

\begin{tabular}{|c|c|c|}
\hline $\begin{array}{l}\text { RESPOSTA: "O entendimento de } \\
\text { lazer e o desejo de discuti-lo" }\end{array}$ & NÚMERO & $\%^{*}$ \\
\hline $\begin{array}{l}\text { SIGNIFICADO DO LAZER } \\
\text { - "É diversão"; "distração"; "é tudo } \\
\text { que se faz para se distrair". } \\
\text { - "É ter vida social"; "dançar"; } \\
\text { "passear", "estar com amigos"; "ir } \\
\text { no clube"; "ir no cinema"; "viajar". } \\
\text { - "É relaxamento". } \\
\text { - "É não pensar em nada"; "arejar a } \\
\text { cabeça". } \\
\text { - "É fazer o que gosta sem } \\
\text { obrigação". } \\
\text { - "É aproveitar as horas de folga". } \\
\text { - "É fazer o que se sente bem". } \\
\text { - "É fazer o que se gosta". }\end{array}$ & $\begin{array}{l}2 \\
2 \\
1 \\
1 \\
1 \\
1\end{array}$ & $\begin{array}{l}20 \\
20 \\
10 \\
10 \\
10 \\
10\end{array}$ \\
\hline $\begin{array}{l}\text { SE GOSTARIA DE CONHECER } \\
\text { E DISCUTIR SOBRE O } \\
\text { ASSUNTONAUTI } \\
\text { - "Sim". }\end{array}$ & 9 & 90 \\
\hline
\end{tabular}

* A \% foi calculada pelo total da população estudada (10). Houve mais de uma resposta em alguns casos

No que tange à questão - "O que você pensa em relação à criação de atividades de lazer e recreação em alguns momentos, no seu serviço", o Quadro 7 nos revela que as respostas demonstram sentimento favorável à aplicabilidade do lazer no serviço, quando $80 \%$ do pessoal investigado expressam ser "ótimo/bom", porque "aproxima as pessoas", "ajuda no relacionamento", desta forma, favorecendo o problema da dificuldade dos contatos e da comunicação entre a equipe. Ainda asseveram, a importância destas atividades no cotidiano profissional para ajudar no "alívio de tensões", "no desligamento dos problemas" e no descanso "da cabeça".

Portanto, podemos constatar que a aplicação das atividades do lazer no ambiente profissional, poderá favorecer a distração, a recreação e o entretenimento, como meio de refazimento das energias, como forma de reeducação e alívio de tensões, contribuindo para a promoção da saúde individual e de toda equipe, bem como, favorecendo a melhoria da qualidade total do serviço, em questão.

REQUIXA (1977), afirma que o indivíduo adaptado ao seu ambiente, participa do seu desenvolvimento. As atividades de lazer conduzem à reeducação e a participação, cria laços afetivos entre o homem e a cidade e/ou ambiente. Ainda, o autor continua acrescentando que os indivíduos devem ser motivados a apropriar-se do seu ambiente, principalmente através da criação de recursos de lazer que sua própria imaginação indicar. Isso desenvolve maior intimidade deste com o meio e conseqüentemente, permitirá o desenvolvimento das relações interpessoais e grupais.

Quadro 7 - Representação numérica e percentual das respostas dos membros da equipe de enfermagem sobre a questão: "o que você acha se houvesse atividades de lazer e recreação em alguns momentos no seu serviço?"

\begin{tabular}{|l|c|c|}
\hline $\begin{array}{l}\text { RESPOSTA: "Existência de hzer } \\
\text { e recreação, no serviço" }\end{array}$ & NUMERO & $\% *$ \\
\hline SENTIMENT O FAVORAVEL AO & & \\
LAZER NO SERVIÇO & 8 & 80 \\
- "Seria ótimo"; "bom". & 2 & 20 \\
- "Aproximaria mais as pes soas"; \\
"ajudaria no relacionamento". & 1 & 10 \\
- "Aliviaria a tensão". & 1 & 10 \\
- "Desligaria um pouco". & 1 & 10 \\
- "Descansaria a cabeça". & & \\
\hline OUTROS & 1 & 10 \\
\hline
\end{tabular}

* A \% foi calculada pelo total da população estudada (10). Houve mais de uma resposta em alguns casos

\section{CONSIDERAÇÕES FINAIS E SUGESTÕES}

Depreendemos então, que os membros da equipe de enfermagem pesquisados, gostam do seu serviço, embora assumindo o caráter desgastante, tenso e estressante do ambiente de trabalho. 
KIMURA (1984) citando Murray (1975) e Reichle (1975) relata que estes sentimentos de depressão, hostilidade e ansiedade freqüentemente encontrados em enfermeiros que trabalham em UTI, resultam de suas experiências constantes com a morte, com situações de extrema gravidade, com emergências, o que exige deles conhecimento especializado, espírito de alerta e habilidade para agir rapidamente. Citando Tomlin (1977), a autora relata também, a ocorrência de graves distúrbios psiquiátricos em enfermeiras de UTI, como consequiência do estresse no ambiente de trabalho. Ainda esta autora em seu estudo, em concordância com Reichle (1975) e Haynes (1978), coloca que o estresse, na equipe de enfermagem da UTI, é resultante das diferentes emoções que dela são esperadas por parte dos pacientes e dos médicos. Estes esperam disciplina e objetividade e aqueles, calor humano. Manter uma atitude que contrabalance estas duas expectativas opostas, é, uma fonte de estresse.

Não obstante, é necessário que se leve em consideração os problemas referentes ao ambiente, visando o bem estar do paciente e dos profissionais em geral que ali atuam. O benefício será revertido na qualidade da assistência, pois que se a equipe de enfermagem estiver constantemente sob estresse, não haverá possibilidade de uma boa atuação, levando-a inclusive, à frustração que, de certo modo, é o primeiro passo para o desinteresse profissional.

A equipe de enfermagem estudada evidencia pois, o serviço enquanto função essencial de assistência, exigindo vocação/ doação, mas também, como estimulador de relacionamento/comunicação/ crescimento. Questionam também, a dura jornada da UTI, sugerindo redução de carga horária, devido suas próprias peculiaridades. Revelam problemas consideráveis de comunicação no serviço, levando a desmotivação profissional. É importante ressaltar que em unidades onde o risco de vida para o paciente é uma constante, esta equipe deve estar preparada para direcionar efetivamente sua observação à comunicação tanto verbal, como não verbal.

Os sujeitos estudados dão sentido real ao significado de lazer, embora de forma simples e ingênua. Todavia, identificam a relevância da distração e do relaxamento no ambiente profissional, sobretudo como meio de comunicação e de alívio de tensões, sendo favoráveis as atividades de lazer no serviço.

Diante dos problemas percebidos e levantados neste estudo, é pertinente ressaltar que vivenciar situações de vida e morte, por esta equipe de enfermagem no cotidiano da UTI, se torna essencial reconheçer seus próprios sentimentos e necessidades, para que livre de ansiedade e tensão, possa assistir melhor os seus pacientes, e conseqüentemente, o ambiente se fará mais agradável para o trabalho.

Sugerimos, assim, que os enfermeiros possam dar atenção especial a esta área em apreço,isto é, a UTI, tendo em vista, o muito que se precisa fazer, para melhoria da qualidade de assistir e de ser assistido.

"Lazer é um conjunto de ocupações às quais o indivíduo pode entregar-se de bom grado, seja para repousar, seja para se divertir, seja para desenvolver sua informação ou formação desinteressada, sua participação social voluntária ou sua livre capacidade criadora...".

(Dumazedier apud REQUIXA, 1977)

\section{LEISURE - ONE WAY TO ALLEVIATE TENSION IN THE ICU WORK ENVIRONMENT - ONE CONCEPTION OF THE NURSING TEAM}

In the present study, we aimed at verifying close to ICU nursing team the service representation and this unit meaning, looking at finding the sense of leisure and its implication in the professional environment. We worked with DUMAZEDIER framework, considering the application of leisure in health promotion, through a quali-quantitative survey. We have investigated 10 members of the nursing team, among different categories, most of them were women, half single, from 28 to 45 years old, with predominantly 10 years in service. They showed pleasure in their job (90\%), although they consider it stressing (50\%). The job was identified as assistance (80\%) and requiring vocation/donation (50\%). They also showed relationship and communication. They have the concept of leisure as entertainment/deconcentration (80\%), relaxation (20\%) etc., emphasizing the importance of discussing the theme. They admit tension/stress caused in the location, considering the need of leisure in the service, to help communication and alleviate the tension. We suggest to nurses special attention on this.

\section{RECREACIÓN - UN CAMINO PARA ALIVIAR LAS TENSIONES EL AMBIENTE DE TRABAJO EN UTI - UNA CONCEPCIÓN DEL EQUIPO DE ENFERMERÍA}


incluyendo el sentido de recreación y su implicación en el ambiente profesional. Trabajamos el referencial teórico de DUMAZEDIER acerca de la aplicación de recreación en la salud, a través de una investigación cualicuantitativa. Investigando 10 miembros del equipo de enfermería, entre las diferentes categorías, mayoría mujeres, mitad solteras, entre 28 y 45 años, predominando 10 años de trabajo (UTI). Evidenciaron gusto al trabajo (90\%), aún siendo desgastante y estresante (50\%), identificaron el trajo como asistencial (80\%), exigiendo vocación/donación (50\%). Cuestionan su jornada de trabajo (60\%). Revelan problemas de relacionamiento y comunicación. Conceptúan recreación como diversión/descontración (80\%), relajamiento (20\%), etc, resaltando la importancia de discutir el asunto. Desprendemos que ellos admiten atención/estress provocado en el trabajo, destacando la necesidad de recreación en el trabajo, para favorecer la comunicación y alivio las tensiones. Sugerimos a los enfermeros atención especial en este sentido.

TÉRMINOS CLAVES: unidad de terapia intensiva (UTI), recreación, equipo de enfermería

\section{REFERÊNCIAS BIBLIOGRÁFICAS}

01.BUENO, S.M.V. Contribuição ao estudo da aplicação do lazer no ambiente hospitalar. Ribeirão Preto, 1981. 236p. Dissertação (Mestrado) - Escola de Enfermagem de Ribeirão Preto, Universidade de São Paulo.

02. _______emântica do binômio saúde/doença. São Paulo, 1993. 150p. Tese (Doutorado) Faculdade de Educação, Universidade de São Paulo.

03. CORRÊA, A. K. Sendo enfermeira no centro de terapia intensiva. Ribeirão Preto, 1995. p.119, Dissertação (Mestrado) - Escola de Enfermagem de Ribeirão Preto, Universidade de São Paulo

04. DUMAZEDIER, J. Lazer e cultura popular. São Paulo: Perspectiva, 1973.

05. .Sociologie empirique du loisir. Paris: Ed. Du Seuil, 1974.

06. Sociologia empírica do lazer: a dinâmica produtora do lazer. São Paulo: Perspectiva, 1979. p. 59.
07. GOMES, A. M. Enfermagem na unidade de terapia intensiva. São Paulo: EPU, 1988. p. 11-25.

08. KIMURA, M. Problemas dos pacientes de unidades de terapia intensiva: estudo comparativo entre pacientes e enfermeiros. São Paulo, 1984. p. 6 7. Dissertação (Mestrado) - Escola de Enfermagem, Universidade de São Paulo.

09. MAGNANE, G. Sociologia do esporte. São Paulo: Perspectiva, 1969.

10. REQUIXA, R. As Dimensões do lazer. Folheto do Serviço Social do Comércio (SESC). São Paulo, Gráfica do SESC, s.d.

11. _ . O lazer nas grandes cidades e os espaços urbanizados. São Paulo: Brasiliense. SESC, 1977. p. 17 - 36. (Cadernos de lazer, 1).

12. SEBASTIANI, R. W. Atendimento psicológico a pacientes internados na UTI. Grupo médico, v. 1, n. 1, p.17-24, s.d.

13. TESCK, E. C. B. Convivência contínua com estresse: vida e trabalho de enfermeiros nas UTIs. Rio de Janeiro, 1982. p.110. Dissertação (Mestrado) - Escola de Enfermagem Ana Neri, Universidade Federal do Rio de Janeiro. 